\section{Validity of the Selective Coefficient of a Behaviour Trait in Hawkmoth Larvae}

In Jamaica the fifth instar larvae of tho New World hawkmoth, Erinnyis ello, exhibit four basic colours: green, blue, green-grey and brown. The green, blue and green-grey larvae feed and rest on the leaves of their commonest food plant (Poinsettia pulcherrima). The brown larvae also feed on these leaves, but they rest for many hours during the day on the base of the trunk, sometimes several yards below where they feed ${ }^{1}$. All the larvae are preyed on during the day by wasps (Polistes crinitus) and to a very small extent by an anole (Anolis lineatopus). Because the wasps search for their prey only in the foliage of the Poinsettia bushes, the three forms staying constantly on its leaves suffer heavily from predation, as selection experiments in the wild have demonstrated ${ }^{1}$. By contrast, all the larvae which rest from time to time on the trunk of the food plant enjoy an almost complete freedom from predators.

From mortality data obtained on the campus of the University of the West Indies in Mona, Kingston, and in neighbouring gardens, a relative selective coefficient of the habit to rest on the trunk was calculated. (I take relative selective coefficient as a quantitative measure for differential survival of different larvae at one particular instar). Because the data showed a vast selective advantage of the order of $V_{t}=88$ per cent (see Table 1 and refs. $2,3,8$ ) and because $V_{t}$ represents the first quantitative assessment of such a value for a behaviour pattern, I decided to check its validity.

Table 1. SELECTIVE COEFFICIENT $V t$ OF THE TRUNK RESTING HABIT IN FIFTH INSTAR LARVAE OF THE HAWKMOTH Erinnyis ello BY THREE DIFFERHAT

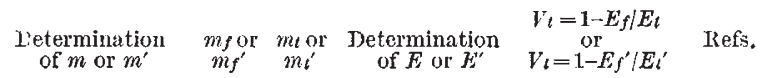

$$
\begin{aligned}
& \text { (1) } m=1-N_{0} \cdot e^{-R} \quad 0.055 \quad 0.007 \quad E=1 /-\ln (1-m) \quad 0.88 \quad 4,5,6
\end{aligned}
$$

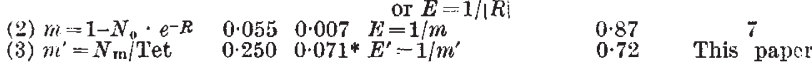

Three different methods were used which are based on two different determinations of the mortality of the larvae per hour of daylight. Fifth instar larvae were placed singly on twigs of Toinsettia bushes in groups from one to forty-six per bush, the average being $6 \cdot 7$ per bush. Altogether 916 individuals of all four colour forms were counted in the foliage, and 131 were found on the trunk (these last had moved down from the foliage). The survivors in each group released were checked after $6.2 \mathrm{~h}$ $(n=162)$ and after $4 \cdot 9 \mathrm{~h}(n=61)$, respectively. (For details of the census technique and of the calculation of the mortality rate, see ref. 1.) The methods used to check the original estimate of $V_{t}$ were as follows:

(1) After it had been ascertained that the mortality rate $m$ was density independent, a constant death rate annong the larvae was assumed. The basic method for the evaluation of $m$ allowed for the variance of the group size and of the time interval between censuses. Because the mortality rates per hour differed only by chance between the four colour forms, the data for all four groups werc pooled to give an overall mortality rate of $m_{f}=0.055$ and of $m_{t}=0.007$ (Table 1, 1), which differ significantly from each other $\left(P<10^{-8}\right)$ (the group on the trunk contained a small percentage of grcen, blue and green-grey Iarvae as well). 'The similarity of the mortality rates of the four colour forms in each respcetive place would be expected if the predator does not hunt by sight which is, in fact, true for the wasps. The resulting relative selective coefficient $V_{t}$ of the habit to rest on the trunk was 88 per cent checked by method 2 .

(2) $m$ was calculated as in method (1), the only difference in calculating $V_{t}$ being in the assessment of $E$ which is probably less accurate ${ }^{8,9}$. But the ensuing selective advantage $V_{t}$ of the trunk group of 87 per cent agrees closely with the value determined by (1) (Table 1, 2).

(3) While the first two methods are independent only with regard to the calculation of the respective life expectancies, the following rather crude estimation of $V_{t}$ is based on another piece of information from the mortality data. Because of algebraic reasons explained elsewhere ${ }^{1}$, twenty-seven counts from the foliage larvae with the total loss of a sample $\left(N_{0}=N_{m}\right)$ have so far had to be omitted from the analysis. They can now be included in the grand total of $N_{m}$ if the number of larvae per hour of daylight killed in each of the two localities is considered (Table 1, 3). Because the initial numbers $N_{0}$ were different in each case, a weighting to compensate for this seemed advisable (see footnote to Table 1). The resulting selective value of 72 per cent is considerably lower than the ones obtained previously but it is based on the simplified assumption that the death rate is a linear function of time. From this it follows that the number of larvae killed after a given time is smaller than if the death rate were constant, that is, it would follow a logarithmic function as has been shown. The deviation from this function of the (simplifying) "linearity model" is negligible if $m$ is very small, as, for example, in the trunk group; accordingly, it must be larger, where $m$ is higher, as, for example, in the foliage group. Thus the difference between $m_{t}^{\prime}$ and $m_{f}^{\prime}$ obtained through the linearity model in this method is smallor than in the more realistic method used before. As a consequence, method (3) must lead to too low a selection coefficient which is confirmed by a comparison of the three methods in Table 1. Moreover, this $V_{t}$ is especially liable to sampling error; if one assumes, for instance, that, in spite of careful searching, I overlooked only one out of the three caterpillars which disappeared from the trunk "population" the $V_{t}$ value would rise to 81 per cent. Thus method 3 actually leads to an estimate of $V_{t}$ which is reasonably close to the two former mothods.

Consequently, the selective disadvantage of the larvae inhabiting the foliage scems so high that some strong advantage should compensate for it. This advantage might lie in the feeding behaviour of an anole. It hunts all over except in the foliage; surprisingly, it preys on non-brown larvae and rejects the brown ones ${ }^{10}$.

This work was supported by the Deutsche Forschungs gemeinschaft. I thank the staff of the Department of Zoology, University of the West Indies, Mona, Kingston, Jamaica (Professor I. Goodbody). Dr H. B. D. Kettlewell (Oxford) kindly improved the English text.

E. CURIO

Arbeitsgruppe für Verhaltensforschung,

Abteilung für Biologio,

Ruhr-Universität Bochum,

463 Bochum, Postfach 2148,

Germany.

Received May 28; revised July 30, 1970.

${ }^{1}$ Curio, E., Verh. Dt. Zool. Ges. (in the press).

2 Kettlewell, H. B. D., Entomology, 2, 831 (1958).

${ }^{3}$ Kettlewell, II. B. D., Ann. Rev. Ent., 6, 245 (1961).

- Farner, I. S., Wilson Bull., 61, 68 (1949).

5 Furner, D. S., Science, 26, 41 (1952).

${ }^{6}$ Leslic, P. H., and Chitty, 1)., Biometrika, 38, 269 (1951).

'Fisher, R. A., and Ford, E. B., Heredity, 1, 143 (1947).

${ }^{3}$ Fidmunds, M., Heredity, 24, 281 (1969).

- Cook, L. M., Brower, L. P., and Croze, H. J., J. Anim. Ecol., 36, 57 (1967).

${ }^{10}$ Curio, 1., Naturwissenschaften, 57, 361 (1970). 